\title{
Practice, complexity and evidence-based practice
}

\author{
Dominic Hurst ${ }^{1}$
}

\section{Key points \\ Explains complexity in relation to} clinical practice.

\author{
Contrasts complexity of practice with \\ linear models of practice articulated in \\ the evidence-based practice literature.

\begin{abstract}
In this opinion piece, I explore practice and complexity, the latter a term often used in relation to the field of special care dentistry. As research is usually concerned with generating new knowledge of some sort, I explore how knowledge is viewed from a practice perspective, as shared, transitory and situated in interactions, rather than being a thing possessed. This leads into a discussion of how the word complexity has been viewed in complexity science, contrasting it with the linear models generated in the evidence-based practice realm from research and research-informed guidelines. Finally, I address the inherent paradox of attempting to align linear models generated from research with the complexity of practice. I suggest that to evaluate and improve practices we should use narrative and exploratory methods that allow its complexity to be made sense of, made transparent and made available for interpretation.
\end{abstract}

\section{Introduction}

In this opinion piece I would like to explore 'complexity', a term often used in relation to this field and, subsequently, what this means when we try to incorporate the outputs of research, such as guideline recommendations, into practice.

As research is usually concerned with generating new knowledge of some sort, I will begin by articulating an understanding of knowledge, or knowing, as being shared, transitory and situated in interactions in practice, rather than being a thing possessed. This will lead into a discussion of how the word complexity is used in complexity science; contrasting it with the linear models generated in the evidence-based practice realm from research and research-informed guidelines. Finally, I will address the inherent paradox of attempting to align linear models

'Queen Mary University of London, Barts and The London School of Medicine and Dentistry, Dental Hospital, Turner Street, London, UK.

Correspondence to: Dominic Hurst

Email: r.d.hurst@qmul.ac.uk

Accepte 19 November 2018

DOI: $10.1038 / s 41415-019-0423-3$ from research with complexity of practice and suggest that to evaluate and improve practices we need methods that allow its complexity to be made sense of, made transparent and made available for interpretation.

\section{Practice and knowing}

Like all other walks of life, special care dentistry involves ongoing interactions between people and things. From a sociomaterial perspective, what we know and what we do is not just dependent on us, but on our social and material interactions. ${ }^{1,2}$ If we site knowing in action, rather than in what clinicians or the clinical team know, then knowing is seen to arise within interactions between people and things. ${ }^{3,4}$ Sociomaterial interactions with patients, families, colleagues and other aspects of the spaces we work in, are unfolding, transient and ephemeral. ${ }^{5,6,7,8}$ Theory development in organisational, ${ }^{6}$ social anthropology ${ }^{9}$ and dental disciplines, ${ }^{10}$ among others, suggests that just as soon as knowing in practices arises, it disappears. Something of the knowing is retained, however, as embodied knowledge, ${ }^{11}$ much of which is tacit. ${ }^{12}$ In our recent article describing GDPs' knowing in practice, Trish Greenhalgh and I theorised that what we come to embody is a knowing of 'practices': a knowing of the experiences of interacting with other people and things, and all the complexity constituted therein. ${ }^{10} \mathrm{We}$ proposed that we then translate this knowing of practices into the ongoing practices we are involved in through what we say and do.

\section{Practice and complexity}

The interactions arising in practice are not chaotic, but nor are they ordered in the way of protocols or plans. Instead, they involve deep and rich embodied knowing of innumerable historical practices translated into the ongoing practice. They go on with a large amount of ignorance, of the others involved, of ourselves, and of the consequences of our interactions. They include great variety of symptoms and signs, of values and wishes, of dexterity and cooperation, of medical histories and medications, of characters and attitudes, and of responses and responsiveness. ${ }^{10}$ Quantity, ignorance and variety of interactions are often associated with descriptions of complexity, a commonly used, though much-contested and difficult to define, term. ${ }^{13}$ 
Using Casti's definition of complexity as a basis, ${ }^{14}$ we could define complexity in dental practice (special care or otherwise) as ongoing, contingent practices arising from the interactions between people and things. From this perspective, complexity is not a substantive thing (such as a complex root canal treatment or a complex medical history). Instead, it arises and disappears within interactions and with each participant perceiving the complexity in their own way. In this way, complexity is not something 'out there' but, like beauty, it is in the eye of the beholder. ${ }^{14}$

In complexity science, the term 'system' is used to denote anything from a cell to the universe. Humans, therefore, are systems that involve ongoing physiological, emotional, or psychological interactions. As systems we interact with other systems, ${ }^{15}$ such as patients and colleagues, as well as non-human systems like computers, wheelchairs, handpieces and medications. Practices share several common properties articulated by complexity science authors, which include: ${ }^{16}$

- Their nonlinearity; for example, we interact with other people and things in ways we cannot predict we will at the start

- Their lack of a single measure that will give a 'true' answer of what happened; for example, there is no single measure of success within a clinical encounter

- Their sensitivity to the initial states of the 'parts' of the system as they interact; for example, clinical encounters are sensitive to the states of us, our patients and other staff, plus the states of our equipment and other objects when we begin the encounter

- Because these parts cannot be controlled perfectly, they tend to become unpredictable; for example, whether or not we and the patient cooperate sufficiently to do treatment

- Their continuous feedback loops and as a result, systematic behaviour arising from innumerable interactions; for example, we and the other people and things respond in the moment to what the others say or do.

While some aspects of an encounter may seem linear and even simple, such as the administration of local anaesthetic infiltration, and some linear but more complicated, such as anaesthesia followed by surgical removal of root, suture placement and analgesia prescription, ${ }^{17}$ these interactions are situated within ongoing practices that are complex and unpredictable. Procedures, even when presented in complicated linear steps such as surgical protocols, do not exist outside of a practice that is complex.

\section{Practice, complexity and evidence- based practice}

The reason for this exposition of practice as complex is to foreground complexity in our discussion about evidence-based practice (EBP). EBP is a paradigm that has adopted a simple linear model of practice. From this viewpoint, practitioners identify research, appraise it, put it into practice and evaluate it. ${ }^{18}$ However, there is a paradox; the research, and the guidelines it informs, usually conclude with simple or complicated linear models of practice, sometimes called knowledge 'products,', ${ }^{19,20}$ that are best represented by 'order' in Figure 1 . Practice, as I have described it above though, is anything but ordered. The linear models generally follow an 'if $\mathrm{X}$ then $\mathrm{Y}$ ' structure. Examples include if a child patient is at high risk of caries, apply fluoride varnish threemonthly; ${ }^{21}$ if a patient has a BPE of four, do a full mouth six-point pocket chart, ${ }^{22}$ if a patient is taking warfarin, actively consider pack and suture following extraction. ${ }^{23}$ As propositional statements, these recommendations are based on research but they do not represent the unfolding, contingent, paradox-laden practices they are intended to be enacted within. They are not situated in the time or history of the practices, not sensitive to the states of people and things as they interact, do not include the variety of phenomena or actions of an unfolding practice. They are not complex.

Gabbay and Le May studied high performing GP practices and showed how good doctors practice good medicine through a diverse range of experiences, most of which were not directly with research evidence artefacts, such as guidelines. Instead, GPs developed what the authors called 'mindlines': 'internalised, collectively reinforced, tacit guidelines that serve as their knowledge-in-practice-incontext $^{24}$ that guided varied, nonlinear, unpredictable and sometimes paradoxical interactions. In addition, actions appear to be interpreted and guided by the actors' general dispositions; for example, a clinician's sense of themselves as caring or a patient's sense of their physical or intellectual ability. ${ }^{10,25}$

The practices in which patients requiring special care and their dental teams engage are always contingent on the events that precede it, by history, the space in which it occurs, and the other people and things involved. How do we deal with the paradox that the output of research is linear and practice is complex?

Gabbay and Le May showed that the linear actions that research suggests leads to better outcomes can be incorporated into practices in some way, despite the complexity of the practices. By focusing on interactions, I think we focus on what we and the patient can accomplish together at this time and in this place, given our respective experiences of other practices. Trish Greenhalgh and I called this 'collective bricolage': the various people and things interacting in a space and time to generate and solve problems in the best way they can. ${ }^{10}$ This will involve paradoxical interactions when what seems right to do here in this situation is at odds with what the guidelines recommend we do; but that is okay. Practice is complex, and paradoxes are expected in complexity.

This is not to suggest that we should not systematically evaluate the practices to which we contribute, nor that this evaluation should

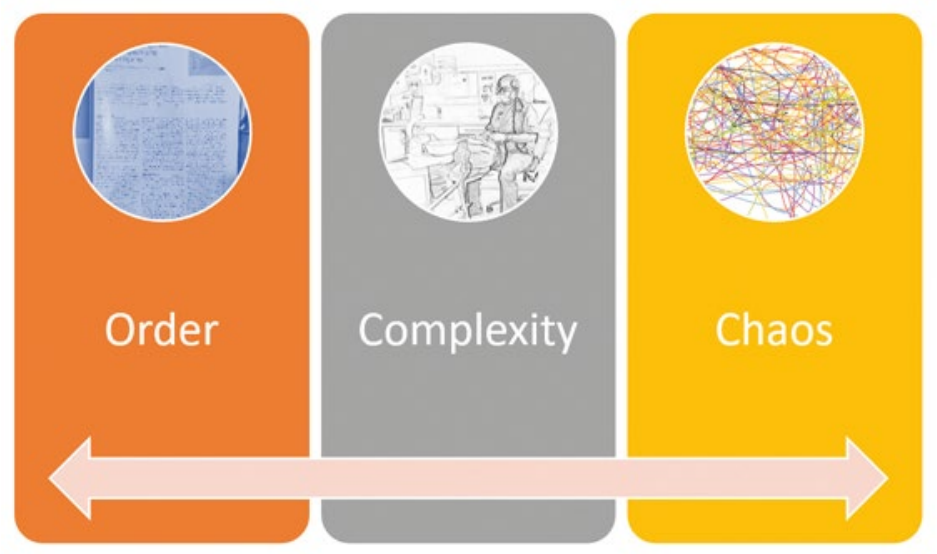

Fig. 1 A representation of order, complexity and chaos 
not be open to external scrutiny. The ways in which we care for patients may need to improve and to find ways of adopting, in some way, the findings of research that may help us do this just as drawing on non-scientific evidence can do. Just because practice is complex doesn't mean we shouldn't ask whether we could improve it in some way. But, I argue, the evaluation and improvement should be situated in practices and include exploration of the values, meanings and other phenomena that arise as people and things interact. To some degree, we do this informally through our discussions with colleagues about cases, and with the norms that develop implicitly in different practising spaces. Stories or narratives, involve plots and, importantly, meaning, with the narrator attempting to make sense of the complexity of events. ${ }^{16}$ However subjective this is, the narration articulates the attempt of the narrator to make sense of complexity and is made available to others to interpret and to learn from, given their experiences. ${ }^{24,26,27,28}$ Work I have conducted with GDPs suggests that narratives provide vicarious experiences that, as well as practical tips of how to do, also convey meaning and value $(\mathrm{PhD}$ thesis in preparation). Early work with GDPs suggest that narratives may allow for a richer, ecological form of knowing to become embodied by others working in similar contexts. ${ }^{29}$ Other formats, such as applied, or forum, theatre ${ }^{30}$ may help to bring into the open the ways in which people and things interact so that they can be felt, meaning made of them and, potentially, challenged in a constructive way. These forms of exploration, unlike those usually involved in scientific research, offer the potential to explore the complexity of aligning the knowing from research with other knowing in ongoing collective accomplishments of practice.

\section{Conclusion}

To conclude, this paper has attempted to articulate a view of practice as complex, emergent and paradox-laden. As a complex system, I have argued that we should explore and be transparent about the paradoxes, meanings and values inherent in practices. I have suggested that more narrative and exploratory methods may be useful ways to make sense of, make transparent and make available for interpretation, these interactions.

\section{References}

1. Orlikowski W J. Sociomaterial Practices: Exploring Technology at Work. Organ Stud 2007; 28: 1435-1448.

2. Orlikowski W J. Knowing in practice: Enacting a collective capability in distributed organizing. Organ Sci 2002; 13: 249-273.

3. Nicolini D. Practice Theory, Work, and Organization: An Introduction. Oxford: Oxford University Press, 2013.

4. Schmidt R. Reflexive Knowledge in Practices. In Hui E, Schatzki T, Shove E (eds) The Nexus of Practices: Connections, Constellations, Practitioners. pp 141-154 Abingdon: Routledge, 2017.

5. Ingold T. Situating action VI: a comment on the distinction between the material and the social. Ecol Psychol 1996; 8: 183-187.

6. Nicolini D, Gherardi S, Yanow D. Knowing in Organizations: A Practice-based Approach. Abingdon: Routledge, 2015.

7. Billett $\mathrm{S}$. Knowing in practice: re-conceptualising vocational expertise. Learn Instr 2001; 11: 431-452.

8. Feldman, M S, Orlikowski W J. Theorizing Practice and Practicing Theory. Organ Sci 2011; 22: 1240-1253.

9. Marchand T H J. Making knowledge: explorations of the indissoluble relation between minds, bodies, and environment. J Royal Anthropol Inst 2010; 16 (Spec Iss): $S 1-S 21$.

10. Hurst $D$, Greenhalgh $T$. Knowing in general dental practice: Anticipation, constraint, and collective bricolage. J Eval Clin Pract 2018; DOI: 10.1111/jep.13051.

11. Loftus S. Embodiment in the Practice and Education of Health Professionals. In Green B, Hopwood N (eds) The Body in Professional Practice, Learning and Education: Body/Practice. pp 139-156. Berlin: Springer International Publishing, 2015.

12. Polanyi M. The Tacit Dimension. Chicago: University of Chicago Press, 2009.

13. Heylighen F, Bollen J, Riegler A (eds). The Evolution of Complexity. Dordrecht: Kluwer, 1995.
14. Casti J L. On System Complexity: Identification, Measurement, and Management. In Casti J L, Karlqvist A (eds) Complexity, Language and Life: Mathematical Approaches. pp 146-173. Berlin: Springer Verlag, 1986.

15. Plsek P E, Greenhalgh T. Complexity science: The challenge of complexity in health care. BMJ 2001; 323: 625-628.

16. Tsoukas H, Hatch M J. Complex Thinking, Complex Practice: The Case for a Narrative Approach to Organizational Complexity. Hum Relat 2001; 54: 979-1013.

17. Enkin M W, Glouberman $S$, Groff $P$, Jadad A R, Stern $A$, Clinamen Collaboration. Beyond evidence: the complexity of maternity care. Birth 2006; 33: 265-269.

18. Dawes M, Summerskill W, Galsziou P et al. Sicily statement on evidence-based practice. BMC Med Educ 2005; 5: 1

19. Brouwers M, Stacey D, O'Connor A. Knowledge creation: synthesis, tools and products. CMAJ 2010; 182: E68-E72.

20. Graham I D, Logan J, Harrison M B et al. Lost in knowledge translation: time for a map? I Contin Educ Health Prof 2006; 26: 13-24.

21. Public Health England. Delivering better oral health: an evidence-based toolkit for prevention. London, UK: Department of Health; 2014.

22. British Society of Periodontology. Basic Periodontal Examination (BPE). 2019. Available at https://www. bsperio.org.uk/publications/downloads/115_090048_ bspbpeguidelines-2019.pdf (accessed May 2019).

23. Scottish Dental Clinical Effectiveness Programme. Management of Dental Patients Taking Anticoagulants or Antiplatelet Drugs. 2015. Available at http:// www.sdcep.org.uk/published-guidance/ anticoagulantsandantiplatelets/ (accessed May 2019).

24. Gabbay J, Le May A. Practice-based Evidence for Healthcare: Clinical Mindlines. Abingdon: Routledge, 2010.

25. Greenhalgh T, Stones R. Theorising big IT programmes in healthcare: strong structuration theory meets actornetwork theory. Soc Sci Med 2010; 70: 1285-1294.

26. Elwyn G, Gwyn R. Stories we hear and stories we tell: analysing talk in clinical practice. BMJ 1999; 318: 186-188.

27. Campion-Smith C, Austin H, Criswick S, Dowling B, Francis G. Can sharing stories change practice? A qualitative study of an interprofessional narrativebased palliative care course. J Interprof Care 2011; 25: 105-111.

28. Currie G, Humpreys M, Waring J, Rowley E. Narratives of professional regulation and patient safety: The case of medical devices in anaesthetics. Health Risk Soc 2009; 11: 117-135.

29. Papakostopoulou M, Hurst D. Disseminating research evidence: what matters to general dental practitioners? Br Dent J 2018; 225: 413-417.

30. Baldwin A. Applied theatre: performing the future. Australas Psychiatry 2009; 17 (Spec Iss): S133-S136. 